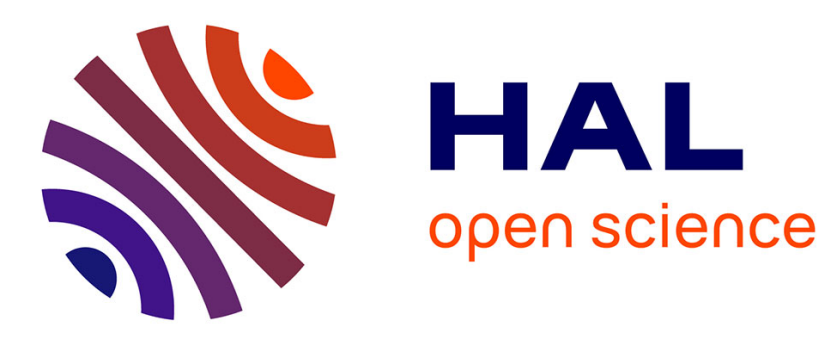

\title{
Buying without using - biases of German BahnCard buyers
}

Hendrik Schmale, Thomas Ehrmann, Alexander Dilger

\section{To cite this version:}

Hendrik Schmale, Thomas Ehrmann, Alexander Dilger. Buying without using - biases of German BahnCard buyers. Applied Economics, 2011, 45 (07), pp.933-941. 10.1080/00036846.2011.613781. hal-00744822

\section{HAL Id: hal-00744822 \\ https://hal.science/hal-00744822}

Submitted on 24 Oct 2012

HAL is a multi-disciplinary open access archive for the deposit and dissemination of scientific research documents, whether they are published or not. The documents may come from teaching and research institutions in France or abroad, or from public or private research centers.
L'archive ouverte pluridisciplinaire HAL, est destinée au dépôt et à la diffusion de documents scientifiques de niveau recherche, publiés ou non, émanant des établissements d'enseignement et de recherche français ou étrangers, des laboratoires publics ou privés. 


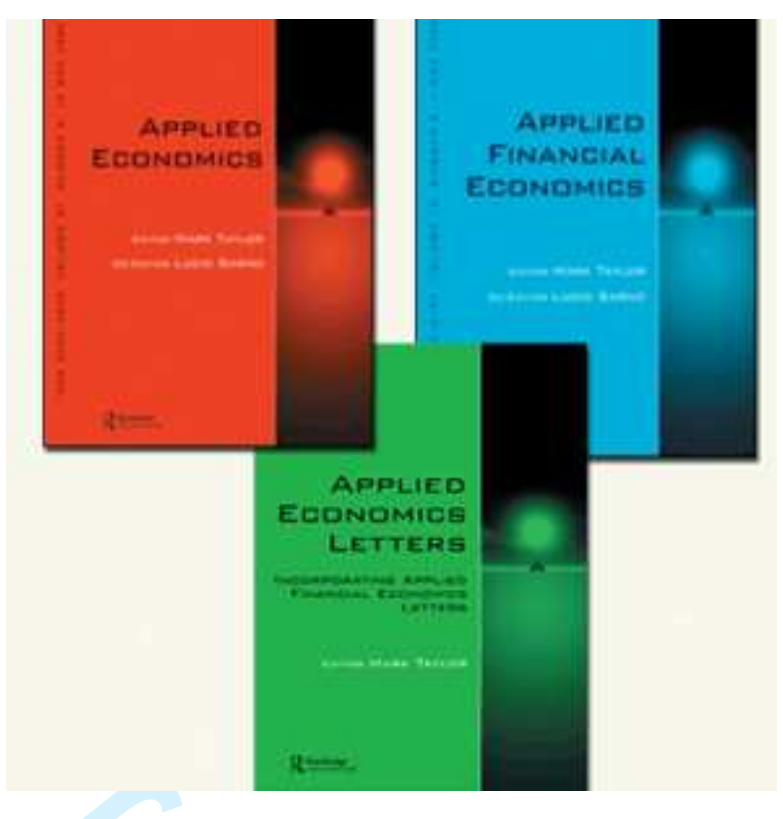

\section{Buying without using - biases of German BahnCard buyers}

\begin{tabular}{|c|c|}
\hline Journal: & Applied Economics \\
\hline Manuscript ID: & APE-2010-0294.R1 \\
\hline Journal Selection: & Applied Economics \\
\hline $\begin{array}{r}\text { Date Submitted by the } \\
\text { Author: }\end{array}$ & 30-Mar-2011 \\
\hline Complete List of Authors: & $\begin{array}{l}\text { Schmale, Hendrik; University of Muenster, Institute of Strategic } \\
\text { Management } \\
\text { Ehrmann, Thomas; University of Muenster, Institute of Strategic } \\
\text { Management } \\
\text { Dilger, Alexander; University of Muenster, Institute for } \\
\text { Organisational Economics }\end{array}$ \\
\hline JEL Code: & $\begin{array}{l}\text { L92 - Railroads and Other Surface Transport: Autos, Buses, etc. < } \\
\text { L9 - Industry Studies: Transportation and Utilities < L - Industrial } \\
\text { Organization, M31 - Marketing < M3 - Marketing and Advertising < } \\
\text { M - Business Administration and Business Econ; Marketing; } \\
\text { Accounting, M21 - Business Economics < M2 - Business Economics } \\
<\text { M - Business Administration and Business Econ; Marketing; } \\
\text { Accounting, D12 - Consumer Economics: Empirical Analysis < D1 - } \\
\text { Household Behavior and Family Economics < D - Microeconomics, } \\
\text { D83 - Search|Learning|Information and Knowledge < D8 - } \\
\text { Information and Uncertainty < D - Microeconomics }\end{array}$ \\
\hline
\end{tabular}




\title{
Buying without using - biases of German BahnCard buyers
}

H. Schmale ${ }^{\mathrm{a}, *}$, T. Ehrmann ${ }^{\mathrm{a}}$ and A. Dilger ${ }^{\mathrm{b}}$

\begin{abstract}
We use a large data set of German railway travellers to analyse the purchasing decision for fare-reducing BahnCards. We expect that this tariff choice is neither completely rational nor irrational, but bounded-rational in a meaningful way. Actually we predict a flat-rate bias, i.e. an under-use of their BahnCards by many customers. However, we estimate that this bias is not too large. The empirical results approve our hypotheses for the most part, especially for the more expensive BahnCard50, whereas the under-use of the cheaper BahnCard25 is so extensive that it is not worthwhile on average.
\end{abstract}

Running title: Buying without using - biases of German BahnCard buyers

\footnotetext{
${ }^{a}$ University of Münster, Institute of Strategic Management, Leonardo-Campus 18, 48149 Münster, Germany

b University of Münster, Institute for Organisational Economics, Scharnhorststrasse 100, 48151 Münster, Germany

* Corresponding author. E-mail: schmale@ism.uni-muenster.de
} 
'Rules of thumb are among the more efficient pieces of equipment of optimal decision making.'

(Baumol/Quandt)

\section{Introduction}

Many firms offer consumers a menu of contracts. Phone users can choose combinations of monthly airtime minutes and prices. Households can opt for different two-part tariffs for electricity (e.g. Salies, 2008). Also railway passengers are often confronted with contractual choices concerning tariffs. They can choose between a high fixed payment ex ante accompanied by a small variable price for every mile travelled and a 'full' price for every mile travelled with no ex ante fixed fee. The consumer has to find the scheme that minimizes the price per mile travelled.

Given the German BahnCard scheme there is an optimal contractual choice for every (expected) quantity of miles travelled by train. A standard assumption in the economics literature is that consumers have rational expectations about their future consumption frequency and choose the utility-maximizing contract. What would be the marginal condition for the optimal decision under imperfect information? It is to equate the marginal costs of additional information gathering with its (expected) marginal benefits and then to decide accordingly. Unfortunately, this condition, that is easily formulated, is very abstract and of little help to estimate accurately the future individual travel demand. In this article we will check how rational the expectations are that consumers have of their future (rail) travel frequency and whether they choose their utility-maximizing contract accordingly. Moreover, we can check whether their decisions have been right ex post.

By now, scholars gained more insight into critical determinants of demand. Specifically, factors such as sunk costs are known to influence consumption (McAfee et al., 2010). From a behavioural economics perspective, prior payment mechanisms, bundling, and timing of payment or purchasing have been analysed with respect to their effects on demand (Thaler, 1985; Wertenbroch, 1998; Gourville and Soman, 1998; Soman, 2001; Soman and Gourville, 2001). For instance, studying public transport acceptance, FitzRoy and Smith (1999) find positive 
impact of fixed fee season tickets on aggregate demand. ${ }^{1}$ However, still not much is known about what affects tariff choice besides expected consumption. Here we try to find out more about the effects of flat-rate pricing (Miravete, 2003). DellaVigna and Malmendier (2004, 2006) famously explain flat-rate biases, i.e. an under-use of contracts by many customers, with overconfidence about time inconsistency, using the example of memberships in fitness clubs.

Consumers may overestimate their demand for a good, e.g. due to producer advertising (Mitchell and Vogelsang, 1991). Drawing on empirical evidence, Nunes (2000) explains how users integrate usage expectation into the decision process when choosing between a flat fee for unlimited access and paying per use. Consumers tend to compare the subjective likelihood of using more than the break-even volume with the subjective likelihood of using less. He finds that consumers habitually overestimate the likelihood of using enough to justify the flatrate and thus falsely favour this payment plan. The perceived range of usage thereby strongly affects the consumers' misperceptions.

Older studies of tariff-choice biases examined the usage of telephone services (Train et al., 1989; Kling and van der Ploeg, 1990). Lambrecht and Skiera (2006) distinguish four different causes for flat-rate biases: the 'insurance effect' (Train, 1991; Miravete, 2002; Winer, 2005), the 'taxi meter effect' (Thaler, 1999), the 'convenience effect' (Kling and van der Ploeg, 1990; Winer, 2005), and the 'overestimation effect' (DellaVigna and Malmendier, 2006). In this article we look more generally at the decision between different choices of fixed and variable fees. We expect to find a flat-rate bias, whatever its reason, but also some bounded rationality.

Our article is the first that analyses a large data set of German railway travellers. This application differs from the so far analysed services in at least two respects. First, demand seems to be more of an exogenous nature than e.g. the visits paid to a gym or internet usage. Second, the monetary outlays, cancellation costs etc. are significantly higher than the respective costs

\footnotetext{
${ }^{1}$ Public transport acceptance has widely been analysed in the context of rising external costs of private transport (e.g. Shen et al., 2008). In a related context, Van Vuuren and Rietveld (2002) estimate the price elasticity of demand for train kilometres considering a two-part tariff option.
} 


\section{Simple Standard Economics and Hypotheses}

We set up a simple framework of contract choice and BahnCard usage. We begin with an analysis of the optimal customer's choice under complete information or ex post, given the train journeys he or she actually made. ${ }^{2}$ Certainly, ex ante the customer does not have complete information and (not) buying a BahnCard is a risky decision. Therefore, the first derived Hypothesis 0 concerning the optimal decision under complete information is only a reference case which we do not expect to be true. Otherwise our analysis could stop there.

A contract $\left(L_{i}, \alpha p\right)$ gives customers the right to use a train for a fee $\alpha p$, once the flat fee $L_{i}$ is paid. $L_{i}$ stands for different fixed fees that induce different variable fee rebates $\alpha$ on $p$. The two extreme cases are the flat-rate $(L, 0)$, the so-called BahnCard100 (BC100) and the payper-mile-tariff $(0, p)$. The most common BahnCards induce either rebates of $25 \%$ or $50 \%$. Consumers can choose between all these contracts.

The discount effect of the BahnCard25 (BC25) with a rebate of $25 \%$ begins at a minimum sum of four times the flat fee in ticket purchases. Let $v$ be the amount spent on rail travel a year (based on the standard fare), then the lower optimality boundary of the BC25 is given by

$$
v \geq L_{25}+0.75 v
$$

\footnotetext{
${ }^{2}$ Both are not the same since buying a BahnCard changes the marginal prices. Complete information implies optimal decisions concerning buying a BahnCard and train tickets later, whereas the reverse is not necessarily true. One can make extra journeys with a BahnCard at hand, even if one would not have bought the card to make these journeys. However, this possible bias in our analysis does not seem to be very important empirically, because most BahnCard holders do use their cards less than optimal although the marginal prices are lower (see below).
} 
and thus,

$$
v_{25}{ }^{l}=L_{25} / 0.25
$$

Assuming a flat fee $L_{25}$ of $€ 57,{ }^{3}$ a yearly spending of $€ 228$ marks the break-even travel volume $v_{25}^{l}$ for the BC25.

More frequent travellers might profit from the BahnCard50 (BC50) which grants a rebate of $50 \%$. One might assume that a BC50 is worth buying if $v$ exceeds twice the flat fee $L_{50}$ since then travel spending is minimized relative to the pay-per-mile tariff. However, in defining the lower optimality boundary of the $\mathrm{BC} 50$ the $\mathrm{BC} 25$ is the relevant benchmark:

$$
L_{25}+0.75 v \geq L_{50}+0.5 v
$$

and thus,

$$
v_{50}^{l}=\left(L_{50}-L_{25}\right) / 0.25
$$

Assuming a flat fee $L_{50}$ of $€ 225$, a yearly spending of $€ 672$ marks the break-even travel volume $v_{50}{ }^{l}$ of the BC50 contract.

Only very frequent travellers profit from a BC100 contract. The lower optimality boundary is given by

$$
L_{50}+0.5 v \geq L_{100}
$$

and thus,

$$
v_{100}^{l}=\left(L_{100}-L_{50}\right) / 0.5
$$

At a price of $€ 3650$, this card is only worth buying if $v$ exceeds $€ 6850$. $^{4}$

\section{Hypothesis 0:}

Agents choose the optimal BahnCard contract for the mileage they travel by train.

We do not think that all or most customers decide optimally ex post. Hypothesis 0 is our reference case and we expect empirical evidence contrary to it. Nevertheless, the lack of complete information and the existence of bounded rationality do not mean the complete lack of

\footnotetext{
${ }^{3}$ This is the current (2009) value.

${ }^{4}$ The optimality intervals of Equations 1 to 6 apply for all $L_{50} \geq 2 \cdot L_{25}$ and $L_{100} \geq 2 \cdot L_{50}$.
} 
all information and total irrationality. On the contrary, we expect some (bounded) rationality even in the mistakes and biases human beings are prone to.

That is why we expect that BahnCards and travel demand are systematically connected. Who anticipates more miles $m$ by train will buy with a higher probability a more expensive BahnCard than someone expecting to travel less miles. Moreover, whereas the individual expectations can be wrong, in the aggregate they are fulfilled more or less. There is a second reason why the owners of more expensive BahnCards will use them more than those of cheaper ones: The marginal price of an additional mile is lower. Unfortunately, we cannot differentiate empirically between these two explanations but both support the following hypothesis.

\section{Hypothesis 1:}

The different contracts $\left(L_{i}, \alpha p\right)$ require different degrees of ex ante commitment of consumers and change marginal prices such that the buyers of more expensive BahnCards accordingly travel more.

$$
m_{100}>m_{50}>m_{25}>m_{0}
$$

Whereas Hypothesis 1 implies at least a weak form of rationality, we expect some deviations from strict rationality, first and foremost a flat-rate bias. A flat-rate bias means that many travellers prefer a (more or less) flat rate even though their billing rate would be lower on a pay-per-mile price. ${ }^{5}$ The magnitude $F$ of a flat-rate bias can be measured by the additional price of the chosen BahnCard and bought tickets compared to the optimal BahnCard and corresponding tickets. For example, buying once a $\mathrm{BC} 100$ ends any worries about the costs of all train trips in the following 12 months. This ease of mind has some value such that paying more than the savings per miles travelled can be boundedly rational. ${ }^{6}$ In the case of the $\mathrm{BC} 100$

\footnotetext{
${ }^{5}$ We follow Nunes (2000) and extend his definition of a flat-rate bias to our context: a flat-rate bias exists when an actor chooses a contract involving a high fixed fee and low variable costs although another contract with a lower fixed fee and higher variable costs would have resulted in a lower billing rate, given his demonstrated demand. In measuring the existence of a flat-rate bias, we follow the common method of measuring the proportion of users in a tariff that would have paid less in a lower tariff, given ex post usage data (see e.g. Mitchell and Vogelsang, 1991; Nunes, 2000; DellaVigna and Malmendier, 2006).

${ }^{6}$ Perfect rationality includes the ability to calculate everything and to make decisions without costs, emotional or otherwise (besides the real costs one is deciding about, of course).
} 
it is also possible to save real transaction and opportunity costs because its owner does not need to buy any more tickets. BC50 and BC25 do not bring about this real convenience but also lower worries and emotional costs for many train tickets.

\section{Hypothesis 2:}

There exists a flat-rate bias among BahnCard holders, i.e. there are many BahnCards which are more expensive than optimal (considering only the BahnCard and ticket fees).

Moreover, we expect that the flat-rate bias is not independent of the kind of BahnCard. Instead $F$ should be higher for more expensive BahnCards. First, it is possible to make greater mistakes with a more expensive card. In the extreme, a BahnCard is not used at all such that the flat-rate bias equals the price of the card. Second, there is a further possibility of mistake. As shown above, it is possible that a BC50 is better than no BahnCard at all but worse than buying a $\mathrm{BC} 25$. This holds for even a larger range of miles when comparing a $\mathrm{BC} 100$ with a BC50.

\section{Hypothesis 3:}

The flat-rate bias is increasing in the price of the BahnCard.

$$
F_{100}>F_{50}>F_{25}
$$

Whereas we expect a flat-rate bias and under-using of many BahnCards, we do not think that the mistakes of BahnCard users are arbitrarily high. On the contrary, the average user probably profits from having the specific BahnCard he or she has (compared to none or any other). This also means that those customers, who have the right BahnCard, profit more by it than the others, having the wrong one, lose. From this it follows that the average utility from a BahnCard is positive.

\section{Hypothesis 4:}

The average utility for BahnCard users is higher with their specific BahnCard than without it. 
What can be said about the different customers' expectations about their own future travel demand? Customers who expect a low travel demand in the future prefer a cheaper BahnCard or none at all. Therefore the option to switch sooner to a lower BahnCard or to paying-permile should be valued highly by them. Customers who view themselves as heavy users in the future should prefer the higher BahnCards. These customers should value the reduced price of each mile travelled and should not mind the yearly commitment. A kind of sorting therefore implies that the higher the chosen contract in the past the more likely these customers should renew a high contract. The renewal probability $R$ of a high contract should be higher than for a low contract.

\section{Hypothesis 5:}

The renewal probability of a more expensive BahnCard is higher than for a cheaper one.

$$
R_{100}>R_{50}>R_{25}
$$

\section{BahnCard Dataset \\ Data and sample period}

Our data were provided by the German railway company Deutsche Bahn (DB) AG and comprise detailed information on customers' individual demographic characteristics, BahnCard contract choices and individual ticket purchase behaviour. The representative sample was drawn from the population of members of the company's customer loyalty programs 'bahn.bonus' and 'bahn.comfort'. The bahn.bonus program awards points to customers based on the amount they purchase. These points can be collected and finally spent on different rewards, e.g. train tickets, $1^{\text {st }}$ class upgrades or car rentals. bahn.comfort is a customer program which awards premium status for customers who spend a predetermined amount of money on ticket purchases. Since customers are rewarded with points for ticket purchases the data set allows for the reproduction of individual travelling behaviour. Based on this information we 
evaluate the efficiency of BahnCard contracts. The sample period is December 2002 through July 2008.

\section{Contractual menu}

Customers can choose between the following contracts: BC25, BC50 and BC100. Each contract is available for the $1^{\text {st }}$ and $2^{\text {nd }}$ class and grants a reduction of either $25 \%, 50 \%$ or $100 \%$ on domestic tickets for 12 months from the date of issue. ${ }^{7}$ In addition to the standard contracts (see Section II), the DB AG offers several reduced fee contracts for students and senior citizens or e.g. family members of $\mathrm{BC} 100$ and $\mathrm{BC} 50$ customers. If not cancelled, $\mathrm{BC} 25$ and BC50 contracts are automatically renewed after 12 months. Cancellation can be done in written form until 6 weeks before the end of validity. BC25 and BC50 customers can switch to higher contracts within the contract period. The residual value of the current card is then refunded. Customers cannot switch to lower contracts during the duration of an ongoing contract.

\section{Sample construction and key variables}

We received data on more than 4 million transactions, each being related to one of approximately 800000 BahnCards and 300000 customers. However, to construct a reliable data base for our analysis we had to make some severe adjustments. Since not all members of the loyalty programs frequently collect bonus points we excluded all customers whose overall lifetime sales volume equals zero. Furthermore, we dropped all customers with nonstandard and promotional contracts. Finally, we concentrated on customers with $2^{\text {nd }}$ class BahnCards, in order to avoid assignment problems and to achieve a maximum comparability between con-

\footnotetext{
${ }^{7}$ This accounts at least for all DB-trains. Parts of the regional passenger rail are operated by other companies. Several of these companies grant reductions on fares for BahnCard customers, too.
} 
tracts. Consequently, our final dataset features 259752 BahnCards of 83263 customers with corresponding transaction data. ${ }^{8}$

With regards to ticket purchases key variables of the dataset include the purchase date, ticket price, reduction rate, class, origin and destination station, number of passengers and a round trip indicator. Since the ticket price represents the reduced price we calculated the standard fare based on the actual reduction rate for each ticket in order to have a common basis of comparison. Inbound and outbound tickets, i.e. travels from or to another country, constitute a special case here. The DB AG offers a 'Railplus' option for BahnCard customers, which grants a $25 \%$ reduction on standard fares for the abroad section when travelling to 29 European countries. For the calculation of standard fares of BC50 customers this poses issues. The ticket price reflects a $50 \%$ reduction on the standard fare of the domestic section and a $25 \%$ reduction on the standard fare of the abroad section. Since we do not have any information on the ratio of domestic to nondomestic route length for these tickets, we assumed that customers realized a reduction of at least $25 \%$ on the entire route. ${ }^{9}$

For our analysis we aggregated all transactional data on a contract basis. Consequently, our final sample features the following information for each BahnCard: Customer ID, reduction rate, flat-fee, date of issue, end of validity, a Railplus dummy, total spending on tickets (including reduction), and virtual total spending on tickets without a BahnCard (hypothetical standard fare). ${ }^{10}$

Our first research question is, whether the chosen contracts are optimal from the customers' perspectives considering individual travelling behaviour. Hence, we calculated the sums of total spending for all possibly available contracts as benchmarks for the actual sum of spend-

\footnotetext{
${ }^{8}$ Despite our adjustments there still might be some unobserved aspects within the data. First, the data originates from a decentralized system which generally aggravates consistent data input. Second, a potential limitation is that customers might exhibit inconsistencies regarding bonus point collection behaviour.

${ }^{9}$ This assumption tends to underestimate reductions of BC50 customers. However, the alternative option would have been to exclude all in- and outbound tickets, which, we feel, would have been an even stronger underestimation of BahnCard reductions. Anyway, the proportion and costs of such trips abroad are quite small (see below).

${ }^{10} \mathrm{BC} 100$ users do not need to purchase tickets and consequently our database lacks information on their travel behaviour. Hence, we cannot draw conclusions on the individual efficiency of $\mathrm{BC} 100$ contracts. Nevertheless, these contracts function as a reference point within the data and represent an important alternative option for $\mathrm{BC} 25$ and $\mathrm{BC} 50$ customers at the end of a contract period.
} 
ing and assigned dummy variables indicating whether the chosen contract was efficient, i.e. cost minimizing, or not. ${ }^{11}$ Specifically, a set of dummies indicate whether or not a lower or a higher contract implies lower costs. Furthermore, a set of variables represent the difference in costs between the actual contract and the alternative options. These variables serve as bases for utility calculation.

Finally, each dataset contains information on the successive contracts indicating if customers switch inefficient contracts or opt out at the end of a contract in order to increase utility.

\section{Descriptive statistics}

Within our sample, $45.9 \%$ of all contracts with transactional data are $\mathrm{BC} 25$ contracts and $54.1 \%$ BC50. Table 1 shows the descriptive statistics for the sample.

[Insert Table 1 about here]

On average, BC25 customers paid $€ 48.04$ as initial fee, BC50 customers paid $€ 140.72$. A typical BC25 customer spends $€ 102.36$ on tickets, BC50 users spend $€ 236.28$. The average spending on in- and outbound tickets is considerably small with €4.62 (BC25) and €7.17 (BC50). Each contract accounts for 2.18 (BC25) and 7.25 (BC50) tickets and generates total costs for the average costumer of $€ 145.39$ (BC25) and $€ 363.77$ (BC50), respectively.

[Insert Table 2 about here]

Table 2 reveals that the typical BahnCard customer is approximately 39 years old at first signup. About $54 \%$ of customers are female and individuals buy on average 3.12 BahnCards during the sample period. The average total spending on tickets for all contracts is $€ 544.70$.

\section{Empirical Results}

We used the data described in Section III to test the hypotheses derived in Section II and got the following results.

\footnotetext{
${ }^{11}$ Several contracts are ongoing at the end of the sample period. In these cases, we included the flat fee on a pro rata basis.
} 


\section{Hypothesis 0 (Optimal Buying Decision for a Particular BahnCard)}

A chi-square goodness-of-fit test ${ }^{12}$ confirms that the null hypothesis, i.e. the frequency distribution of optimal contracts in our sample is consistent with the theoretical distribution $(100 \%)$, can be rejected at a significance level of $p<.001 .^{13}$ In particular, we assigned a dummy variable indicating whether a certain contract is cost minimizing (optimal=1) or not (optimal $=0$ ), given demonstrated demand. In fact, only $29.7 \%$ of contracts were within the respective optimality boundaries as derived in Section III. As stressed above, we actually did not expect that all users decide optimally ex post, and consequently, Hypothesis 0 is not supported by our data.

\section{Hypothesis 1 (Higher Travel Demand by Users of More Expensive BahnCards)}

Table 3 illustrates the results of an independent-samples $t$-test. ${ }^{14}$ The test variable is total annual spending on tickets (based on the standard fare), with BC50 and BC25 contracts representing the two samples. BC25 customers spend on average the amount of $€ 144.30$ on tickets, this being significantly less than the average spending of BC50 users (€484.51). Consequently, we find strong support for Hypothesis 1.

[Insert Table 3 about here]

\section{Hypothesis 2 (Existence of a Flat-Rate Bias)}

Table 4 shows the results of a nonparametric sign test, which is commonly used when only the direction of differences is of interest, not the magnitude (Conover, 1999). We constructed two variables current BahnCard and optimal BahnCard and assigned values (0, 25, 50, and 100) according to the reduction rates of the actual contract and the contract which would have

\footnotetext{
${ }^{12}$ The methods applied in this section arise from the specific hypothesis formulations as well as from the scale of the criterions under consideration. When comparing rates and proportions, we resort to the commonly applied class of chi-square methods (e.g. Fleiss et al., 2003). Considering interval-scaled data we apply both parametric and nonparametric methods in order to enhance the robustness of our results.

${ }^{13}$ This test tests whether the frequency distribution of certain events observed in a sample is consistent with a particular theoretical distribution. The events have to be mutually exclusive with a total probability of 1 . Since the approximation to the chi-square distribution breaks down if expected frequencies are too low $(<5$, see Gibbons and Chakraborti, 2003), we slightly relaxed the strong assumption of no sub-optimal contracts to the lower boundary.

${ }^{14}$ Since we only included completed contracts, $n$ scales down to the total of 216157 observations. The underlying assumptions of the $t$-test are homogeneity of variances in the two samples and the criterion under consideration has to be interval-scaled. Furthermore, the $t$-test requires normal distribution of the sample-mean, which is given for large sample sizes $(n>30)$ according to the central limit theorem (Greene, 2008). However, we corrected for heterogeneous variances, and a nonparametric Mann-Whitney-U-Test confirmed our results (e.g. Daniel, 2000).
} 
minimized total (monetary) costs, given demonstrated demand. The sign test poses the null hypothesis optimal BahnCard = current BahnCard and tests whether positive and negative differences between a random pair of measurements are equally likely to occur. Considering Hypothesis 2 we should observe a higher probability for the case optimal BahnCard < current BahnCard.

[Insert Table 4 about here]

In $67 \%$ of cases customers under-used their BahnCard, i.e., switching to a lower contract or to the pay-per-mile tariff would lower total monetary costs. In only $3.3 \%$ of cases BahnCards were over-used, i.e. switching to a higher contract would minimize costs. $29.7 \%$ of contracts are optimal. The null hypothesis can be rejected at a significance level of $p<.001$. Thus, our data corroborate the existence of a flat-rate bias and consequently Hypothesis $2 .^{15}$

\section{Hypothesis 3 (Higher Flat-Rate Bias of More Expensive BahnCards)}

We conducted an independent-samples $t$-test with the test variable being defined as the difference in costs between the optimal contract plus corresponding tickets and the chosen BahnCard and bought tickets. As we only consider under-used contracts $n$ scales down to 173 969 with BC25 (88 828) and BC50 (85 141) contracts representing the two samples. Our results support Hypothesis 3 ( $p<.001$, Table 5). On average, BC25 users with under-used contracts incurred losses of $€ 35.45$. BC50 users incurred losses of $€ 96.68$. $^{16}$

[Insert Table 5 about here]

\section{Hypothesis 4 (BahnCards are Useful on Average)}

We calculated the utility of the actual contract based on the comparison to the ex post optimal regime. In particular, for under-using BC50 customers either the $\mathrm{BC} 25$ or no BahnCard is the cost minimizing option. The test variable is defined as absolute value of the difference in costs of the chosen BahnCard and ticket purchases and the price of the ex post optimal contract and corresponding tickets. ${ }^{17}$ As Table 6 shows, losses due to under-usage are on average

\footnotetext{
${ }^{15}$ We conducted another chi-square goodness-of-fit test which confirms that the frequency distribution of suboptimal contracts in our sample is not consistent with the theoretical distribution of $0 \%(p<.001)$.

${ }^{16}$ A further Mann-Whitney-U-Test was highly significant, too.

${ }^{17}$ For optimally used contracts, utility is calculated based on the comparison to the next worst contract, i.e. the lower boundary.
} 


\section{[Insert Table 6 about here]}

Hence, Hypothesis 4 is mainly corroborated by our data, with the exception that the average utility of the $\mathrm{BC} 25$ sub-sample is negative.

\section{Hypothesis 5 (Higher Renewal Probabilities for More Expensive BahnCards)}

We conducted a chi-square test of independence and assigned a dummy variable indicating whether a customer holds on to his or her initial contract (renewal=1) or not, i.e. whether the user opts out or switches the contract (renewal $=0)$. Contract type $(25,50)$ was the second variable under consideration in our contingency table. Hypothesis 5 is substantiated by the data. The renewal probability increases for more expensive BahnCards as BC50 customers are 1.1 times as likely to renew contracts as BC25 customers $(p<.001$, Table 7).

[Insert Table 7 about here]

\section{Discussion and Implications}

There is empirical evidence in favour of most of our hypotheses. Most buyers of a BahnCard did not make the ex post optimal buying decision but they showed a flat-rate bias. Nevertheless, their decisions were not completely irrational but they showed, at least in the aggregate, bounded rationality. Interestingly, the buyers of the more expensive BC50 made fewer mistakes than those of the cheaper $\mathrm{BC} 25$, whose buyers lost on average. Perhaps the $\mathrm{BC} 25$ is cheap enough that it is not worthwhile to bother about it.

Analysing real transactional data, our article provides valuable insights into customers' contract choice and optimization behaviour. Going into more detail, further research should scrutinize the cost side of customer decision making. As long as we do not know more about con- 
sumers' cognitive costs, it will remain difficult to determine the adequate point of comparison. This might be illustrated by the example of considering upper boundaries, i.e. over-usage becomes a mistake, too: As BahnCards can be upgraded virtually anytime throughout contract duration, customers are forced to optimize continuously during the year; when only considering lower boundaries customers must make just two decisions, one at the beginning and another one at the end of the period. Taking upper boundaries into account implies that the number of time consuming and rationally demanding (i.e. costly) decisions increases dramatically. Moreover, as decisions get more complicated, the point where the marginal costs of additional information gathering equate its (expected) marginal benefits could be reached very soon, making results that are inefficient in a frictionless world the optimal ones in a second best world.

While we concentrated on the customers of BahnCards so far, there are some interesting implications for the selling side. Offering BahnCards seems to be a very good idea for the DB AG because the flat-rate bias brings a double dividend. Both the BahnCards and the reduced pay-per-mile fees bring in money and the net effect is clearly positive. Lower fees per mile encourage more traffic and the BahnCard fees more than compensate the lower price per mile whereas the number of miles can be expected to be higher together with the total revenues. We do not know the costs of DB AG but they are probably mainly fixed such that the profits are up, too.

Another interesting question for future research is the optimal structure of BahnCards, both for the customers and the seller. Would more BahnCards, e.g. a BahnCard75 or a BahnCard10 be a good idea? Rational customers could only win and never lose by more alternatives, because users can better adapt contract choice to individual travel habits. However, the outcome is less clear for bounded-rational customers. For instance, more alternatives come with a narrowing of optimality intervals which implies a higher probability of error. Sellers can win by more price discrimination but there are also potential downsides. For example, customers might take the anticipated regret of an erroneous decision into account, which - in the worst case - might dissuade them from choosing any option with increasing likelihood of failure. 
Furthermore, aspects such as e.g. raising costs of segmentation need to be considered, in order to obtain a comprehensive picture of the outcome of more price discrimination. 


\section{References}

Conover, W. J. (1999) Practical Nonparametric Statistics, 3rd edn, John Wiley \& Sons, New York.

Daniel, W. W. (2000) Applied Nonparametric Statistics, 2nd edn, PWS-Kent, Boston.

DellaVigna, S. and Malmendier, U. (2004) Contract Design and Self-Control: Theory and Evidence, Quarterly Journal of Economics, 119, 353-402.

DellaVigna, S. and Malmendier, U. (2006) Paying Not to Go to the Gym, American Economic Review, 96, 694-719.

FitzRoy, F. and Smith, I. (1999) Season Tickets and the Demand for Public Transport, Kyklos, 52, 219-238.

Fleiss, J. L., Levin, B. and Paik, M. C. (2003) Statistical Methods for Rates and Proportions, 3rd edn, John Wiley \& Sons, New York.

Gibbons, J. D. and Chakraborti, S. (2003) Nonparametric Statistical Inference, 4th edn, Marcel Dekker, New York.

Gourville, J. T. and Soman, D. (1998) Payment Depreciation: The Behavioral Effects of Temporally Separating Payments from Consumption, Journal of Consumer Research, 25, $160-74$.

Greene, W. H. (2008) Econometric Analysis, 6th edn, Prentice Hall, Upper Saddle River, NJ.

Kling, J. P. and Ploeg vd, S. S. (1990) Estimating Local Elasticities with a Model of Stochastic Class of Service and Usage Choice, in Telecommunications Demand Modelling. An Integrated View, (Eds) A. de Fontenay, M. H. Shugard and D. S. Sibley, North Holland, Amsterdam, pp. 119-36.

Lambrecht, A. and Skiera, B. (2006) Paying Too Much and Being Happy About It: Existence, Causes and Consequences of Tariff-Choice Biases, Journal of Marketing Research, 43, 212-23.

McAfee, R. P., Mialon, H. M. and Mialon, S. H. (2010) Do Sunk Costs Matter?, Economic Inquiry, 48, 323-36. 
Miravete, E. J. (2002) Estimating Demand for Local Telephone Service with Asymmetric Information and Optional Calling Plans, Review of Economic Studies, 69, 943-71.

Miravete, E. J. (2003) Choosing the Wrong Calling Plan? Ignorance and Learning, American Economic Review, 93, 297-310.

Mitchell, B. M. and Vogelsang, I. (1991) Telecommunication Pricing: Theory and Practice. Cambridge University Press, Cambridge, UK.

Nunes, J. C. (2000) A Cognitive Model of People's Usage Estimations, Journal of Marketing Research, 37, 397-409.

Salies, E. (2008) Mergers in the GB electricity market: effects on retail charges, Applied Economics, 40, 1483-90.

Shen, J., Sakata, Y. and Hashimoto, Y. (2008) Is individual environmental consciousness one of the determinants in transport mode choice?, Applied Economics, 40, 1229-39.

Soman, D. (2001) Effects of Payment Mechanism on Spending Behavior. The Role of Rehearsal and Immediacy of Payments, Journal of Consumer Research, 27, 460-74.

Soman, D. and Gourville, J. T. (2001) Transaction Decoupling: How Price Bundling Affects the Decision to Consume, Journal of Marketing Research, 38, 30-44.

Thaler, R. H. (1985) Mental Accounting and Consumer Choice, Marketing Science, 4, 199214.

Thaler, R. H. (1999) Mental Accounting Matters, Journal of Behavioral Decision Making, 12, 183-206.

Train, K. E. (1991) Optimal Regulation. The Economic Theory of Natural Monopoly, MIT Press, Cambridge, MA.

Train, K. E., Ben-Akiva, M. and Atherton, T. (1989) Consumption Patterns and Self-Selecting Tariffs, Review of Economic and Statistics, 71, 62-73.

Van Vuuren, D. and Rietveld, P. (2002) The Off-Peak Demand for Train Kilometers and Train Tickets, Journal of Transport Economics and Policy, 36, 49-72.

Wertenbroch, K. (1998) Consumption Self-Control via Purchase Quantity Rationing, Marketing Science, 17, 317-37.

Winer, R. S. (2005) Pricing, Marketing Science Institute, Cambridge, MA. 


\section{Tables and Figures}

Table 1. Descriptive statistics contracts

\begin{tabular}{lll}
\hline Contracts & BC25 & BC50 \\
\hline $\begin{array}{l}\text { number of contracts } \\
\quad \text { total }\end{array} \quad 119,240$ & 140,512 \\
$\quad$ completed & 101,597 & 114,560 \\
initial fee & 48.04 & 140.72 \\
& $(14.86)$ & $(50.17)$ \\
total spending on tickets & & \\
$\quad$ incl. reduction & 102.36 & 236.28 \\
& $(206.53)$ & $(402.33)$ \\
\multicolumn{1}{c}{ hypothetical standard fare } & 136.48 & 467.78 \\
& $(275.38)$ & $(797.49)$ \\
total spending on abroad tickets & 4.62 & 7.17 \\
& $(37.53)$ & $(58.46)$ \\
total costs & 145.39 & 363.77 \\
& $(210.03)$ & $(419.49)$ \\
number of tickets & 2.18 & 7.25 \\
& $(5.08)$ & $(12.94)$ \\
n & 119,240 & 140,512 \\
\hline $\begin{array}{l}\text { Notes: } \text { Standard deviation in parentheses. A completed contract ends } \\
\text { before the date of data retrieval. }\end{array}$ & & \\
& &
\end{tabular}

Table 2. Descriptive statistics customers

\begin{tabular}{ll}
\hline Customers & \\
\hline age at first contract & 38.66 \\
& $(17.59)$ \\
female & 0.54 \\
& $(0.50)$ \\
total spending on tickets & 544.70 \\
& $(1057.92)$ \\
number of contracts & 3.12 \\
& $(1.69)$ \\
$\mathrm{n}$ & 83,263 \\
\hline Notes: Standard deviation in parentheses. Total \\
spending on tickets includes reduction.
\end{tabular}


Table 4. Empirical results - sign test

\begin{tabular}{ll}
\hline Hypothesis 2 & \multicolumn{1}{c}{$\mathrm{N}$} \\
\hline optimal BahnCard < current BahnCard & 173,969 \\
optimal BahnCard $>$ current BahnCard & 8,643 \\
optimal BahnCard = current BahnCard & 77,140 \\
\hline $\mathrm{N}$ & 259,752 \\
$\mathrm{Z}$ & -386.88 \\
$\mathrm{P}$ & $<.001$ \\
\hline
\end{tabular}

Table 5. Empirical results - flat-rate-bias by contracts

\begin{tabular}{lrrrr}
\hline Hypothesis 3 & $\mathrm{N}$ & Mean & SE & $\mathrm{p}^{*}$ \\
\hline utility BC25 under-use & 88,828 & -35.45 & .064 & \\
utility BC50 under-use & 85,141 & -96.68 & .192 & \\
difference & & 61.23 & .202 & $<.001$ \\
\hline
\end{tabular}

* p values from independent samples t-test.

Table 6. Empirical results - average utility

\begin{tabular}{lrrrr}
\hline Hypothesis 4 & $\mathrm{N}$ & \multicolumn{1}{c}{ Mean } & \multicolumn{1}{l}{ SE } & $\mathrm{p}^{*}$ \\
\hline utility (absolute value) under-use & 173,969 & 65.41 & .124 & \\
utility (absolute value) optimal use & 85,783 & 142.58 & .681 & \\
Difference & & -77.17 & .692 & $<.001$ \\
utility (absolute value) BC25 under-use & 88,828 & 35.45 & .064 & \\
utility (absolute value) BC25 optimal use & 30,412 & 68.61 & .554 & \\
Difference & & -33.16 & .557 & $<.001$ \\
utility (absolute value) BC50 under-use & 85,141 & 96.68 & .192 & \\
utility (absolute value) BC50 optimal use & 55,371 & 183.21 & .968 & \\
difference & & -86.53 & .987 & $<.001$ \\
\hline *p values from independent samples t-test. & & & &
\end{tabular}


Table 7. Empirical results - contract renewal probability

\begin{tabular}{|c|c|c|c|c|c|}
\hline Hypothesis 5 & & Renewal & No & Yes & Total \\
\hline \multirow[t]{4}{*}{ Contract } & BC25 & $\mathrm{N}$ & 11,498 & 28,004 & 39,502 \\
\hline & & $\%$ of contract & 29.1 & 70.9 & 100 \\
\hline & BC50 & $\mathrm{N}$ & 8,351 & 30,026 & 38,377 \\
\hline & & $\%$ of contract & 21.8 & 78.2 & 100 \\
\hline \multirow[t]{2}{*}{ Total } & & $\mathrm{N}$ & 19,849 & 58,030 & 77,879 \\
\hline & & $\%$ of contract & 25.5 & 74.5 & 100 \\
\hline$\chi^{2}$ & & & 553.27 & & \\
\hline$\tilde{\mathrm{Df}}$ & & & 1 & & \\
\hline $\mathrm{P}$ & & & $<.001$ & & \\
\hline$\Phi$ & & & .084 & & \\
\hline
\end{tabular}

